\title{
Oncology

\section{Physicians' and Patients' Knowledge of Cancer Screening - A Wake-Up Call}

\section{David Klemperer}

Ostbayerische Technische Hochschule Regensburg, Regensburg, Germany

\section{Introduction}

Physicians serve the health and wellbeing of individual people and the population in general. The highest imperative for a physician should be to preserve and restore a patient's health. Every medical intervention should take place while maintaining and respecting the will, rights, and autonomy of the patient. Physicians are obliged to further their knowledge as required for the purposes of their profession. Thus, they must be aware of the most current state of knowledge (evidence) relating to the medical topics that make up their work [1]. The following observations are intended to shed light on the fact that physicians are not satisfying the demands of their profession when it comes to questions of cancer screening. This article seeks to highlight the problem and present a call to action.

Cancer screening programs are aimed at people who do not present any of the symptoms associated with the illness in question. The purpose of bringing forward diagnosis and the start of therapy is to achieve better results regarding mortality and morbidity in comparison to diagnosing when symptoms have become manifest. Thus, cancer screening intends first and foremost to reduce the death rate associated with the type of cancer in question and, by extension, overall mortality. As yet, the latter has not been demonstrated for any form of cancer, which could be related to the fact that incidence and mortality rates lie in the lower, one-digit percentage range, even for the comparatively more common cancers, and the studies were not large enough to record any major difference. For instance, the risk of a 65 -year-old to develop colorectal cancer within the next 10 years is $2.4 \%$, and $6.4 \%$ for the remaining life span; the mortality risk for the coming 10 years is $0.9 \%$ and for the remaining life span $3.0 \%$ [2].

A reduction in the mortality rate through screening has been demonstrated for colorectal cancer, breast cancer, and cervical cancer; correspondingly, screening for these 3 types of cancer has been incorporated into the catalog of benefits of the statutory health insurance providers. There are no studies for other forms of cancer which demonstrate that the advantages outweigh the disadvantages. With respect to prostate cancer, for example, the benefits of early detection are uncertain and, if at all existent, may be only marginal. The harm related to overdiagnosis or overtreatment is, however, certain and serious. Up to this point, studies on the early detection of ovarian carcinoma have not brought any reduction in mortality, but the damage due to overdiagnosis and overtreatment is clearly manifest. The following explores selected studies about the knowledge of physicians and patients on the benefits and risks of cancer screening.

\section{How Informed Are Physicians?}

A survey of American general physicians and internists revealed serious gaps in the basic understanding of cancer screening [3]. Nearly half of the primary physicians agreed with the wrong statement, i.e. that the higher number of diagnosed tumors in a screened versus an unscreened group in a randomized, controlled study provided evidence that screening saves lives. The opposite may be true: screening can increase incidence and mortality at the same time, as demonstrated for neuroblastoma screening [4]. Furthermore, $76 \%$ were unaware of the phenomenon of lead-time bias, and thought incorrectly that the increase in the 5-year survival rate was proof that early detection saves lives [5]. Only $22 \%$ recognized that this statement is false. An increase in the 5-year survival rate from 68 to $99 \%$ - which is irrelevant information - makes physicians more likely to recommend cancer screening than the relevant information of a reduction in mortality from 2 to 1.6 per 1,000 (numbers taken from the European study on prostate cancer screening) $[3,6]$.

\begin{tabular}{ll}
\hline KARGER & (2) 2014 S. Karger GmbH, Freiburg \\
2296-5270/14/3715-0008\$39.50/0 \\
$\begin{array}{l}\text { Fax +49 76145207 14 } \\
\begin{array}{l}\text { Information@Karger.com } \\
\text { www.karger.com }\end{array}\end{array}$ & $\begin{array}{l}\text { Accessible online at: } \\
\text { www.karger.com/ort }\end{array}$
\end{tabular}


A study that surveyed 65 German physicians yielded no better results [7]. 76\% thought that the 5-year survival rate demonstrated the benefit of screening, and only 1 of the 65 physicians was in a position to adequately explain lead-time bias.

The evaluation of consultations by 20 gynecologists to provide basic information on mammography screening produced the following problematic results [8]: When questioned on the risk of a 55-year-old woman of actually having breast cancer, the gynecologists responded either with qualitative information (i.e. breast cancer is the most common form of cancer) or with lifetime incidence. For the most part, they expressed the information qualitatively and not numerically. Only 1 gynecologist named all-cause mortality as a criterion for benefit. The disease-specific benefit was communicated mainly as a relative risk reduction, a measure that does not reflect the actual benefit [9]. Information on the risks was consistently incomplete. No gynecologist addressed the problem of overdiagnosis and overtreatment [10]. In the rare cases in which quantitative information was communicated, the established standards for risk communication were not applied.

The trend towards a one-sided emphasis on the benefit and neglect of the risks became clear in a study involving 34 Austrian general physicians and internists. When providing information on the prostate-specific antigen (PSA) test, the physicians rarely discussed the risks and potential damage. A portion of the doctors said that they saw no sense in confusing the patients, but they may not actually have had the required knowledge at hand [11].

These studies leave no doubt that many doctors are not in a position to inform their patients adequately of the benefits and harms of cancer screening.

\section{How Informed Are the Patients?}

Patients mirror the level of information found among physicians. The majority of American citizens surveyed in 2000 and 2001 believed that cancer screening is always good and will always or almost always save lives. Many viewed non-participation in screening as irresponsible. Most even welcomed full-body computed tomography. The authors view the results as problematic enthusiasm for cancer screening [12].

In a more recent American study, only 30 of the 317 persons surveyed in the age range of 50-69 years indicated that their doctor had discussed the problem of overdiagnosis and overtreatment in connection with early cancer detection. However, $80 \%$ would welcome information on the associated risks. $51 \%$ of all participants would not start a screening procedure that led to more than 1 overtreatment per life saved. $69 \%$ would not start screening if the overdiagnosis rate was 10 or more instances per life saved - as is likely the case with mammography screening and certainly the case with the PSA test [13].
In a German study from 2008, three-quarters of those surveyed agreed with the incorrect statement that participation in cancer screening was not associated with any medical risks at all [14].

A Europe-wide study, which surveyed more than 10,000 citizens in 9 European countries, revealed that $92 \%$ of women and $98 \%$ of men had inflated concepts of the benefit of early detection for breast cancer and/or prostate cancer [15].

In a recent German study, women born between 1949 and 1968 (insured by BARMER GEK) were surveyed regarding their knowledge of the benefits and risks of mammography screening [16]. This study made clear that the majority of women did not have the evidence-based knowledge about the benefits and risks necessary for an informed decision. Given the lack of knowledge on the part of gynecologists, this is no surprise [6].

\section{Conclusion and Outlook}

Patients express substantial levels of trust in their doctors: 93.7\% trust general practitioners and $93.3 \%$ trust specialists [17]. At the moment, however, this trust is unwarranted when it comes to information on questions of cancer screening. The aforementioned studies demonstrate a significant lack of knowledge among physicians and insufficient patient information concerning the benefits and harms of early cancer detection. Hence, physicians are violating their own ethical standards as defined in the introduction.

The reasons for this knowledge deficit among physicians must be identified primarily in their education and postgraduate training, in which they are not, or insufficiently, exposed to the required information. Financial and other interests among physicians who carry out screening procedures may present an obstacle to the acceptance of information concerning the risks of early detection. However, there is a solution to this problem. The persons responsible in the self-governance of the medical profession are obliged to guarantee the quality and safety of medical practice towards the public. There is a need for comprehensive and mandatory training of doctors with 2 objectives: acquisition of the required basic knowledge regarding the various cancer screening programs and the adoption of communication skills that enable the patient to make an independent assessment of the benefits and harms and thus to give real informed consent. This also corresponds with the requirements defined in the cancer screening and registration law and the corresponding new § 25a SGB V (Social Code Book). One concrete step in this direction is an online training program, currently under development by the Kassenärztliche Vereinigung Bayern (Bavarian Association of Statutory Health Insurance Physicians) and the Techniker Krankenkasse. The goal of this further education is to provide doctors with the necessary skills to enable patients to make an informed decision for or against participating in colorectal cancer screening programs. 


\section{Disclosure Statement}

The author declares that he is a paid scientific advisor for the development of the online training program of the Kassenärztliche Vereinigung Bayern (Bavarian Association of Statutory Health Insurance Physicians) and the Techniker Krankenkasse.

\section{References}

1 German Medical Association (Sample): Code of Medical Ethics for German Physicians, as of 2011.

2 Robert Koch Institute (RKI); (GeKiD): Cancer in Germany 2006/2010, ed 9. Federal Health Report, 2013, p 38.

3 Wegwarth O, Schwartz LM, Woloshin S, Gaissmaier W, Gigerenzer G: Do physicians understand cancer screening statistics? A national survey of primary care physicians in the United States. Ann Inter Med 2012;156:340-349.

4 Schilling FH, Spix C, Berthold F, et al.: Neuroblastoma screening at one year of age. $\mathrm{N}$ Engl $\mathrm{J}$ Med 2002;346:1047-1053

5 Wegwarth O, Gigerenzer G: Risikokommunikation: Sterblichkeitsstatistik als valides Maß. Dtsch Arztebl 2011;108:A-760/B-624.

6 Schroder FH, Hugosson J, Roobol MJ, et al.: Screening and prostate-cancer mortality in a randomized European study. N Engl J Med 2009;360: $1320-1328$.

7 Wegwarth O, Gaissmaier W, Gigerenzer G: Deceiving numbers. Survival rates and their impact on doctors' risk communication. Med Decis Making 2011;31:386-394.
8 Wegwarth O, Gigerenzer G: 'There is nothing to worry about': gynecologists' counseling on mammography. Patient Educ Couns 2011;84:251-256.

9 Wegwarth O, Gigerenzer G: Risikokommunikation: Risiken und Unsicherheiten richtig verstehen lernen. Dtsch Arztebl 2011;108:A-448/B-360.

10 Welch HG, Black WC: Overdiagnosis in cancer. J Natl Cancer Inst 2010;102:605-613.

11 Malli G: Früherkennung von Prostatakrebs mittels PSA-Test: Ergebnisse aus einer qualitativen Studie zu arztseitigen Barrieren bei der Umsetzung der informierten Entscheidungsfindung in Österreich. Gesundheitswesen Online-Publikation 2012; DOI: dx.doi.org/10.1055/s-0032-1309017.

12 Schwartz LM, Woloshin S, Fowler FJ, Welch G: Enthusiasm for cancer screening in the United States. JAMA 2004;291:71-78.

13 Wegwarth O, Gigerenzer G: Overdiagnosis and overtreatment: evaluation of what physicians tell their patients about screening harms. JAMA Intern Med 2013;173:2086-2087.
14 Kickbusch I, Marstedt G: Gesundheitskompetenz: eine unterbelichtete Dimension sozialer Ungleichheit; in Böcken J, Braun B, Amhof R (eds): Gesundheitsmonitor 2008. Gesundheitsversorgung und Gestaltungsoptionen aus der Perspektive der Bevölkerung. Gütersloh, Bertelsmann Stiftung, 2008, p 14.

15 Gigerenzer G, Mata J, Frank R: Public knowledge of benefits of breast and prostate cancer screening in Europe. J Natl Cancer Inst 2009;101:1216-1220.

16 Schmacke N, Dierks ML: Mammografie-Screening und informierte Entscheidung - mehr Fragen als Antworten. Gesundheitsmonitor 2014. Gütersloh, Bertelsmann-Stiftung, 2014.

17 Braun B, Marstedt G: Gesundheitspolitik auf dem Prüfstand; in Böcken J, Braun B, Landmann J (eds): Gesundheitsmonitor 2010. Bürgerorientierung im Gesundheitswesen. Gütersloh, Bertelsmann Stiftung, 2010, p 272. 